\title{
Erratum to: Refractory urticaria in adult-onset Still's disease
}

\author{
Han-Chi Tseng $\cdot$ Chih-Hung Lee
}

Published online: 11 March 2014

(C) Springer-Verlag Berlin Heidelberg 2014

\section{Erratum to: Rheumatol Int}

\section{DOI 10.1007/s00296-014-2952-z}

Inadvertently, the corresponding author was identified incorrectly in the original publication of this article. The complete affiliations of both the authors were not published. The complete affiliations are given below.

The online version of the original article can be found under doi:10.1007/s00296-014-2952-z.

H.-C. Tseng · C.-H. Lee $(\bowtie)$

Department of Dermatology, Kaohsiung Chang Gung Memorial

Hospital and Chang Gung University College of Medicine,

Kaohsiung, Taiwan, ROC

e-mail: dermlee@gmail.com

H.-C. Tseng

e-mail: perkyjoy@hotmail.com 